\title{
Photoelectrochemical Deposition of SnSe Thin Films on a Se-Modified Polycrystalline Gold Substrate ${ }^{\dagger}$
}

\author{
Sunyoung Ham, Seungun Choi, ${ }^{\ddagger}$ Yujin Chae, ${ }^{\ddagger}$ Woo Ju Lee, ${ }^{\ddagger}$ Ki-Jung Paeng, Whan-Gi Kim, ${ }^{\ddagger}$ and Noseung Myung ${ }^{\ddagger}{ }^{\star}$ \\ Department of Chemistry, Yonsei University, Wonju Campus, Wonju, Kangwondo 220-710, Korea \\ ${ }^{\ddagger}$ Department of Applied Chemistry, Konkuk University Chungju Campus, Chungju, Chungbuk 380-701, Korea \\ *E-mail: myung@kku.ac.kr \\ Received July 15, 2010, Accepted August 7, 2010
}

Key Words: Photoelectrochemistry, SnSe, Photocorrosion, EQCM, Semiconductor

Tin selenide ( $\mathrm{SnSe}$ ) has attracted attention of many researchers due to its many interesting electrical and optical properties such as high absorption coefficients, which are useful for optoelectronic applications in memory switching devices, solar cells and holographic reading systems. ${ }^{1-5}$ Also, it is composed of earth abundant, cost-effective and environmentally benign elements. ${ }^{1}$ Therefore, much effort has been devoted to the synthesis of SnSe thin films by a variety of methods like vacuum deposition, ${ }^{4}$ chemical bath deposition, ${ }^{6}$ electrodeposition ${ }^{2,3,7}$ as well as electrochemical atomic layer epitaxy (ECALE) ${ }^{8}$ Recently, Brutchey and co-workers reported that $\mathrm{SnSe}$ nanocrystals synthesized by a solution-phase route exhibited quantum confinement effects, showing band gap increase from the bulk value of $1.30 \mathrm{eV}$ to $1.71 \mathrm{eV}$. The increased band gap matches well with the visible region of the solar spectrum, which implies more efficient utilization of solar energy in that region.

Electrochemical deposition has been widely used for the synthesis of semiconductor thin films because this technique has several advantages such as simplicity, low cost, possibility of using irregular surfaces, and room temperature operation. ${ }^{9}$ However, this technique is fraught with problems related to film composition which varies with experimental conditions such as electrodeposition potential. ${ }^{10}$ To improve the purity of the films, a two step method has been developed. ${ }^{11}$ This approach is based on the initial electrochemical modification of the substrate with $\mathrm{Se}$ (for example, in case of CdSe), followed by the reductive stripping of $\mathrm{Se}$ to $\mathrm{Se}^{2-}$ in $\mathrm{Se}(\mathrm{IV})$ free electrolytes dosed with $\mathrm{Cd}^{2+}$ ions to generate CdSe on the substrate. This approach has been successfully used to synthesis of iron sulfide, ${ }^{12}$ cadmium selenide, ${ }^{11}$ cadmium telluride, ${ }^{13}$ and zinc telluride $^{14}$ films or particles. However, the two step approach cannot be employed for the synthesis of some semiconductor films such as $\mathrm{SnSe}$ since $\mathrm{Sn}^{2+}$ is reduced to $\mathrm{Sn}$ before pre-electrodeposited $\mathrm{Se}$ is reduced to $\mathrm{Se}^{2-}$. In this Note, we describe for the first time photoelectrochemical deposition route for the synthesis of SnSe semiconductor thin films, which is based on the initial electrodeposition of Se on the substrate and subsequent photoexitation (photocorrosion) of $\mathrm{Se}$ to $\mathrm{Se}^{2-}$ in electrolytes containing $\mathrm{Sn}^{2+}$ ions to produce $\mathrm{SnSe}$.

\footnotetext{
${ }^{\top}$ This paper is dedicated to Professor Hasuck Kim for his outstanding contribution to electrochemistry and analytical chemistry.
}

\section{Experimental}

Details of the electrochemical instrumentation and the electrochemical quartz crystal microgravimetry (EQCM) set-up are described elsewhere. ${ }^{15}$ An EG\&G Princeton Applied Research (PAR) 263A instrument equipped with Model M250/270 electrochemistry software and a Seiko EG\&G Model QCA 917 were used for microgravimetry and voltammetry. A $9 \mathrm{MHz}$ ATcut gold-coated quartz crystal (geometric area, $0.2 \mathrm{~cm}^{2}$ ), a Pt wire and $\mathrm{ag} / \mathrm{AgCl} / 3 \mathrm{M} \mathrm{NaCl}$ were used as a working electrode, counter electrode and reference electrode, respectively. All potentials below are quoted with respect to this reference electrode. Prior to the electrodeposition experiments, the cleanliness of the gold electrode was checked by cyclic voltammetry in $0.1 \mathrm{M} \mathrm{H}_{2} \mathrm{SO}_{4}$. The potential was cycled between $-0.8 \mathrm{~V}$ and $0.7 \mathrm{~V}$ until the voltammetric and frequency signals were stable.

Tin(II) chloride dihydrate (purity 98\%), selenium dioxide (purity 99+\%), hydrochloric acid (purity 37\%), sodium sulfate (purity 99+\%), sulfuric acid (purity 98+\%) were obtained from Aldrich. All chemicals were used as received.

A Müller Elektronik-Optik tungsten halogen lamp was used as the light source. The light intensity measured on the electrode surface with a Newport Model 70260 radiant power meter combined with a Model 70268 probe was $\sim 100 \mathrm{~mW} / \mathrm{cm}^{2}$ in all the experiments described below. This value is uncorrected for cell reflection and electrolyte absorption losses. Film morphology and composition were obtained on a field emission scanning electron microscope (Hitachi S4800) equipped with an energy dispersive X-ray (EDX) analysis probe. The X-ray diffraction patterns (XRD) were obtained with a Philips XPERT-MPD instrument using a $\mathrm{Cu} \mathrm{K} \alpha$ radiation source.

\section{Results and Discussion}

Figure 1(A) shows a combined cyclic voltammogram and simultaneous frequency changes in the dark for the Se-modified Au electrode in $0.1 \mathrm{M} \mathrm{Na}_{2} \mathrm{SO}_{4}$. For the preparation of a Se-modified $\mathrm{Au}$ electrode, $-0.6 \mathrm{~V}$ was applied to the $\mathrm{Au}$ electrode for $300 \mathrm{~s}$ in $10 \mathrm{mM} \mathrm{SeO}_{2}$ dissolved in a $0.1 \mathrm{M} \mathrm{Na}_{2} \mathrm{SO}_{4}$ solution. As shown in the figure, selenium stripping to $\mathrm{Se}^{2-}$ begins at $\sim-0.7 \mathrm{~V}$, which is manifest from the cathodic wave and frequency increase (mass decrease). During the returning scan, electrochemically reduced $\mathrm{Se}^{2-}$ is again oxidized to $\mathrm{Se}^{0}$ from $\sim-0.5 \mathrm{~V}$, 

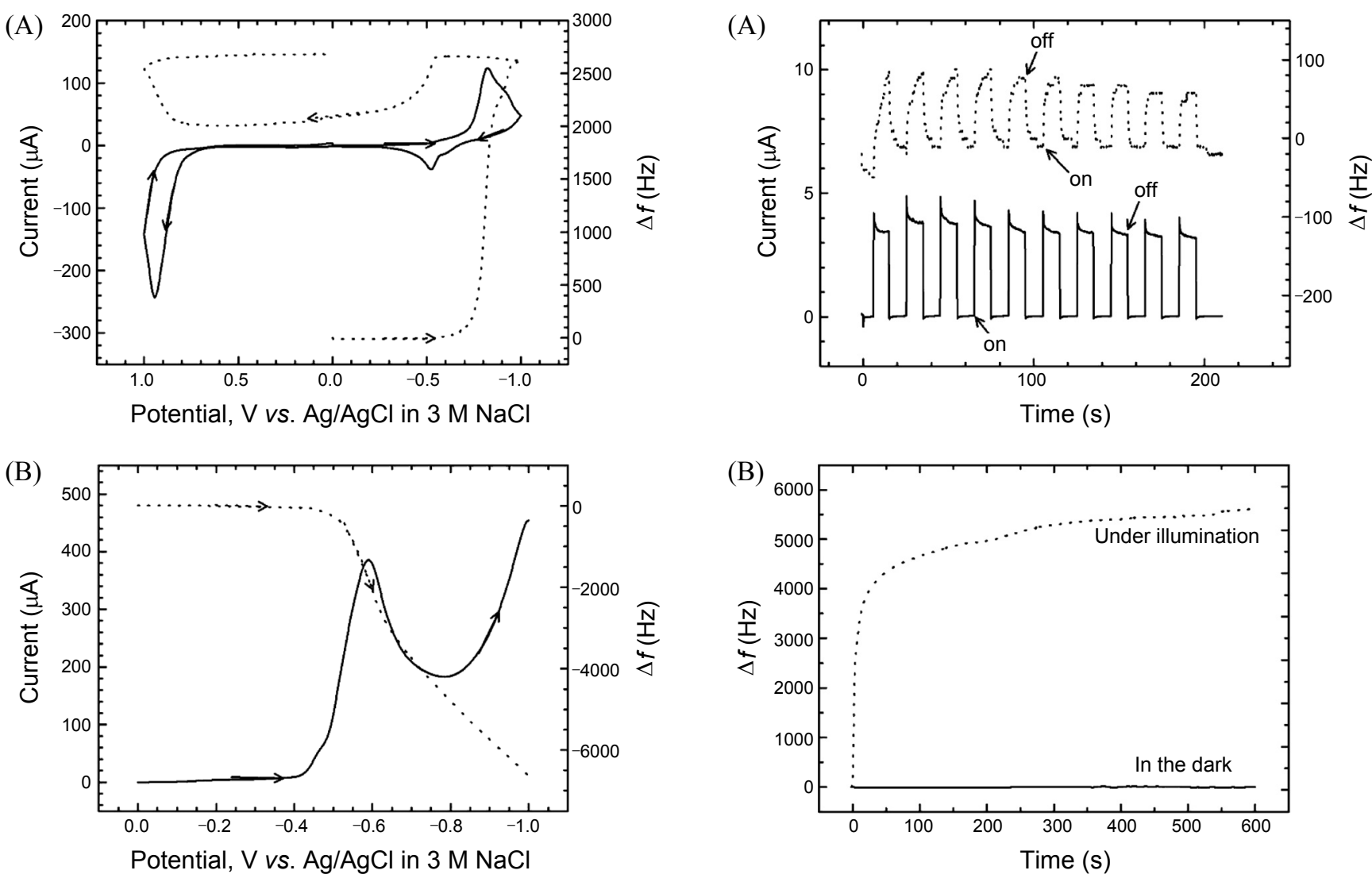

Figure 1. (A) Combined cyclic voltammogram (-) and the corresponding frequency changes (----) for the Se-modified $\mathrm{Au}$ electrode in $0.1 \mathrm{M} \mathrm{Na}_{2} \mathrm{SO}_{4}$. Se was pre-electrodeposited using a $0.1 \mathrm{M} \mathrm{Na}_{2} \mathrm{SO}_{4}$ electrolyte containing $10 \mathrm{mM} \mathrm{SeO}_{2}$ at $-0.6 \mathrm{~V}$ for $300 \mathrm{~s}$. (B) Linear sweep voltammogram (-) and the corresponding frequency changes (---) in the dark for the Au electrode in $0.1 \mathrm{M} \mathrm{HCl}$ electrolyte containing $1 \mathrm{mM} \mathrm{SnCl}_{2}$. Scan rate: $10 \mathrm{mV} / \mathrm{s}$.

which is obvious from the mass increase and concomitant anodic wave. Another anodic wave and frequency increase at $\sim+0.9 \mathrm{~V}$ can be assigned to the oxidation of $\mathrm{Se}$ to $\mathrm{Se}^{4+}$. Note that no electrochemical reactions are shown between potentials for $\mathrm{Se}^{2-}$ oxidation to $\mathrm{Se}$ and $\mathrm{Se}$ oxidation to $\mathrm{Se}^{4+}$ in the dark.

Figure 1(B) demonstrates that the two step approach cannot be employed for the synthesis of SnSe semiconductor films. This figure contains data obtained from the linear sweep voltammogram and accompanied frequency changes for the $\mathrm{Au}$ electrode in $0.1 \mathrm{M} \mathrm{HCl}$ electrolyte containing $10 \mathrm{mM} \mathrm{SnCl}_{2}$. From the mass increase and cathodic wave, it is evident that tin deposition begins at $\sim-0.5 \mathrm{~V}$. Two voltammograms in the Figure 1 clearly implies that a new approach is required for the electrochemical synthesis of $\mathrm{SnSe}$ thin films.

To demonstrate the photoelectrochemical deposition of $\mathrm{SnSe}$ thin films using a photocorrosion of Se, we investigated photoelectrochemical behavior of electrodeposited Se films. Well known is that selenium is a p-type semiconductor which shows cathodic photocurrent upon light illumination and produces $\mathrm{Se}^{2-}$ by photocorrosion. ${ }^{11}$ Figure 2(A) shows photocurrent response and accompanied frequency changes of the Se-modified $\mathrm{Au}$ electrode in $0.1 \mathrm{M} \mathrm{Na}_{2} \mathrm{SO}_{4}$ electrolyte at $-0.3 \mathrm{~V}$. Again, Se was pre-electrodeposited on the Au electrode by holding the po-

Figure 2. (A) Photocurrent transients (-) and corresponding EQCM frequency changes (----) at $-0.3 \mathrm{~V}$ for the Se-modified Au electrode in $0.1 \mathrm{M} \mathrm{Na}_{2} \mathrm{SO}_{4}$ electrolyte. (B) Frequency changes for the Se-modified $\mathrm{Au}$ electrode at $-0.3 \mathrm{~V}$ in $0.1 \mathrm{M} \mathrm{Na}_{2} \mathrm{SO}_{4}$ in the dark (-) and under illumination (----).

tential at $-0.6 \mathrm{~V}$ for $300 \mathrm{~s}$ in $10 \mathrm{mM} \mathrm{SeO}_{2}$ dissolved in a $0.1 \mathrm{M}$ $\mathrm{Na}_{2} \mathrm{SO}_{4}$ solution. The cathodic photocurrent generated when the light is switched on reveals that as deposited Se acts as a p-type semiconductor. ${ }^{11}$ At the same time, frequency increase implies that the $\mathrm{Se}$ is photoelectrochemically reduced to $\mathrm{Se}^{2-}$ by the photocorrosion. Interestingly enough, electrode mass is increased when the light is switched off, showing that $\mathrm{Se}$ is electrodeposited on the Au electrode again. This can be understood since electrochemically generated $\mathrm{Se}^{2-}$ is oxidized at the potential of $-0.3 \mathrm{~V}$ as seen in the Figure 1(A).

Next, Figure 2(B) demonstrates that Se can be completely reduced by the photocorrosion at a fixed potential of $-0.3 \mathrm{~V}$ in $0.1 \mathrm{M} \mathrm{HCl}$. Again, a Au electrode was pre-modified with Se by holding a potential at $-0.6 \mathrm{~V}$ for $300 \mathrm{~s}$ in $0.1 \mathrm{M} \mathrm{Na}_{2} \mathrm{SO}_{4}$ electrolyte containing $10 \mathrm{mM}$ of $\mathrm{SeO}_{2}$. While no frequency changes are observed in the dark, frequency increase (mass decrease) by photocorrosion is complete within $\sim 600$ s upon light illumination on the selenium-modified Au electrode surface. The fact that $\mathrm{Se}$ is reduced to $\mathrm{Se}^{2-}$ by photocorrosion at the potential at which $\mathrm{Sn}^{2+}$ is not reduced to $\mathrm{Sn}$ reveals the possibility of the photoelectrochemical deposition of SnSe films.

Data in Figure 3(A) clearly demonstrate that SnSe can be synthesized when $\mathrm{Se}$ is reduced to $\mathrm{Se}^{2-}$ by photocorrosion in electrolyte dosed with $\mathrm{Sn}^{2+}$ ions. As shown in Figures 2(B) and $3(\mathrm{~A})$, mass change is zero in the dark condition in both cases 

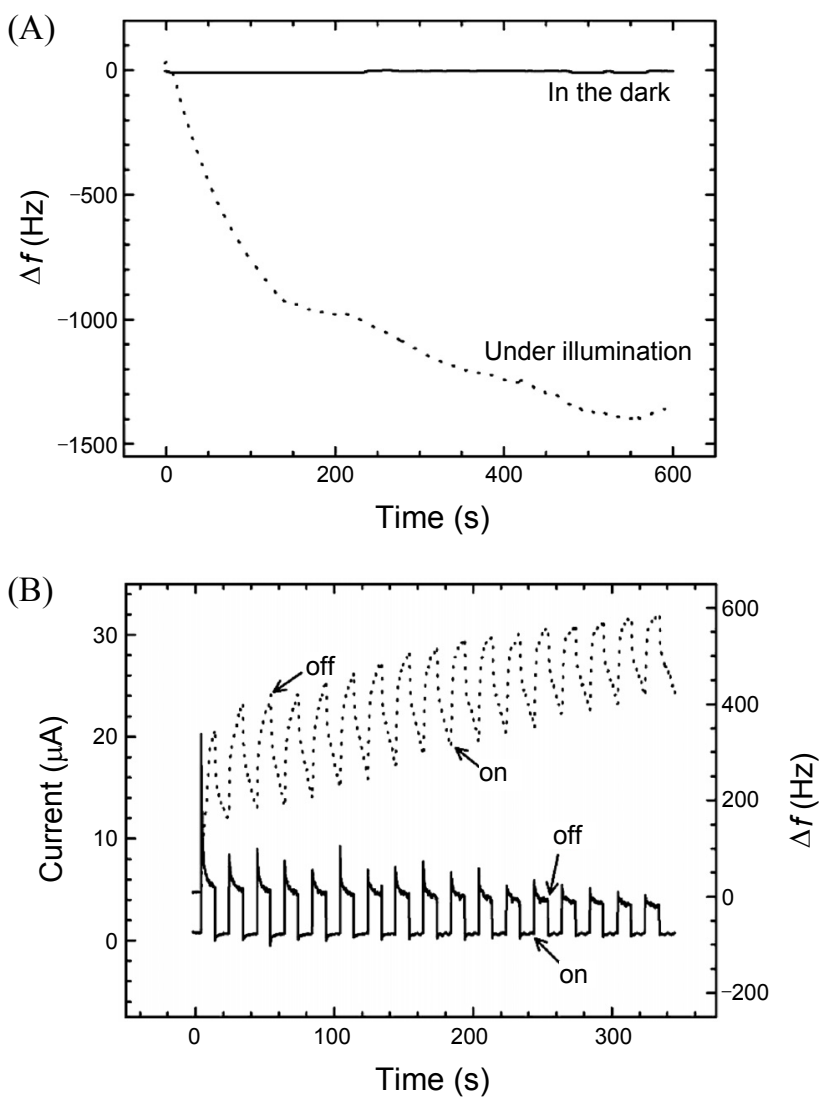

Figure 3. (A) Frequency changes for the Se-modified Au electrode at $-0.3 \mathrm{~V}$ in $0.1 \mathrm{M} \mathrm{HCl}$ containing $1 \mathrm{mM}$ of $\mathrm{SnCl}_{2}$ in the dark $(-)$ and under illumination (----). (B) Photocurrent transients (-) and corresponding EQCM frequency changes (----) for the SnSe-modified $\mathrm{Au}$ electrode at $-0.3 \mathrm{~V}$ in $0.1 \mathrm{M} \mathrm{Na}_{2} \mathrm{SO}_{4}$ electrolyte. SnSe was photoelectrochemically synthesized using the conditions described in Figure 3 (A) and excess Se was stripped by applying a fixed potential of $-0.9 \mathrm{~V}$ for $600 \mathrm{~s}$ in $0.1 \mathrm{M} \mathrm{Na}_{2} \mathrm{SO}_{4}$.

when $\mathrm{Sn}^{2+}$ ions are either absent or present. However, on irradiation of the Se modified Au electrode at $-0.3 \mathrm{~V}$ in $0.1 \mathrm{M} \mathrm{HCl}$ containing $1 \mathrm{mM}$ of $\mathrm{SnCl}_{2}$, frequency decreases quickly signaling mass gain by the reaction of $\mathrm{Se}^{2-}$ generated by photocorrosion with $\mathrm{Sn}^{2+}$ to produce $\mathrm{SnSe}$ films on the Au electrode surface:

$$
\begin{aligned}
& \text { Photocorrosion: } \mathrm{Se}+2 \mathrm{e}^{-}=\mathrm{Se}^{2-} \\
& \text { Precipitation reaction: } \mathrm{Se}^{2-}+\mathrm{Sn}^{2+}=\mathrm{SnSe}
\end{aligned}
$$

Figure 3(B) contains chronoamperometry and EQCM data obtained from the SnSe modified Au electrode at a fixed potential of $-0.3 \mathrm{~V}$ in $0.1 \mathrm{M} \mathrm{Na}_{2} \mathrm{SO}_{4}$. Prior to the experiment in Figure 3(B), excess Se was cathodically removed by applying a fixed potential of $-0.9 \mathrm{~V}$ in $0.1 \mathrm{M} \mathrm{Na}_{2} \mathrm{SO}_{4}$ blank electrolyte for $600 \mathrm{~s}$. Again, photocurrent is cathodic, indicating that photoelectrochemically deposited $\mathrm{SnSe}$ film is p-type semiconductor. ${ }^{5,16}$ The photocurrents are due to the SnSe since excess Se was cathodically removed prior to the photoelectrochemical experiment in Figure 3(B). As shown in the figure, frequency increases when the light is switched on and mass is regained with the light
(A)

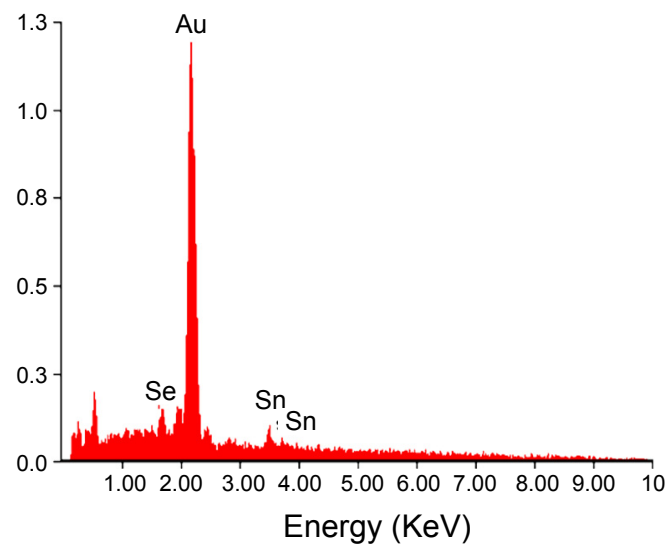

(B)

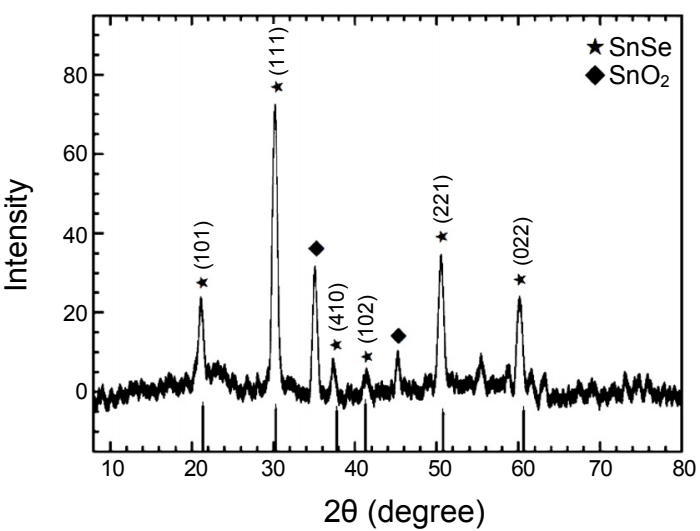

Figure 4. (A) EDX analysis of SnSe thin film. The excess Se was cathodically removed by the procedure in Figure 3(B). (B) The XRD pattern for the SnSe film annealed at $300{ }^{\circ} \mathrm{C}$ for $1 \mathrm{~h}$ in air.

switched off. Systematic change of frequency with light on-off cycles is consistent with the photocorrosion of $\mathrm{SnSe}$ to $\mathrm{Sn}+$ $\mathrm{Se}^{2-}$ with the light switched on and re-deposition of Se when the light is switched off since the potential is enough for the oxidation of $\mathrm{Se}^{2-}$ to $\mathrm{Se}$. However, it is evident that not all $\mathrm{Se}^{2-}$ is oxidized to Se since the EQCM frequency does not attain its original level. Therefore, $\mathrm{SnSe}$ is photocorroded to $\mathrm{Sn}$ and $\mathrm{Se}^{2-}$, resulting in increase of frequency and decrease of photocurrent as the light on-off cycles repeat. More efficient photoelectrolyte should be developed to suppress photocorrosion of SnSe films.

The successful synthesis of SnSe films is further demonstrated using EDX spectroscopy and XRD analysis. As shown in Figure 4(A), EDX analysis revealed that the SnSe films contained $\mathrm{Sn}$ and $\mathrm{Se}$ with a ratio of $1: 1.1$, in agreement with the stoichiometric composition of SnSe. Also, the XRD pattern for the SnSe films deposited on the ITO electrode by the photoelectrochemical approach shows diffraction lines at $2 \theta=$ $21.395^{\circ}, 30.307^{\circ}, 38.131^{\circ}, 41.279^{\circ}, 50.722^{\circ}$ and $60.650^{\circ}$, which are in good agreement with the reported values for SnSe (JPCDS File No. 32-1382). The films were annealed at $300{ }^{\circ} \mathrm{C}$ for $1 \mathrm{~h}$ in air before the XRD measurement.

In summary, we demonstrated that SnSe thin films can be photoelectrochemically synthesized on the Se-modified Au electrode by employing photocorrosion of $\mathrm{Se}$ to $\mathrm{Se}^{2-}$ and precipitation reaction of $\mathrm{Se}^{2-}$ with $\mathrm{Sn}^{2+}$. Thus synthesized $\mathrm{SnSe}$ acted as a p-type semiconductor with a stoichiometric ratio of 
about 1:1.1 after stripping of excess Se. The approach described in this Note could be used for the synthesis of Se- or Te-containing semiconductor or thermoelectric materials such as SnTe, $\mathrm{Sb}_{2} \mathrm{Se}_{3}$ or $\mathrm{Sb}_{2} \mathrm{Te}_{3}$. Further studies on the synthesis of $\mathrm{SnSe}$ nanoparticles or nanostructured films by a PEC deposition approach, and applications to the fabrication of semiconductor sensitized solar cells using wide band gap semiconductors like $\mathrm{ZnO}$ and $\mathrm{TiO}_{2}$ will be carried out in our laboratories.

Acknowledgments. This research was supported by the Basic Science Research Program through the National Research Foundation of Korea (NRF) funded by the Ministry of Education, Science and Technology (2009-0074367) and the National Research Foundation of Korea Grant funded by the Korean Government (MEST) (NRF-2009-C1AAA001-0093168).

\section{References}

1. Franzman, M. A.; Schlenker, C. W.; Thompson, M. E.; Brutchey, R. L. J. Am. Chem. Soc. 2010, 132, 4060.

2. Zainal, Z.; Ali, A. J.; Kassim, A.; Hussein, M. Z. Sol. Energy Mater. Sol. Cells 2003, 79, 125.
3. Engelken, R. D.; Berry, A. K.; Doren, T. P. V.; Boone, J. L.; Shahazary, A. J. Electrochem. Soc. 1986, 133, 581.

4. Chandra, G. H.; Kumar, J. N.; Rao, N. M.; Uthanna, S. J. Crystal Growth 2007, 306, 68 .

5. Tuğluoğlu, N.; Karadeniz, S.; Sahin, M.; Safak, H. Appl. Surf. Sci. 2004, 233, 320.

6. Pejova, B.; Grozdanov, I. Thin Solid Films 2007, 515, 5203.

7. Subramanian, B.; Mahaligam, T.; Sanjeeviraja, C.; Jayachandran, M.; Chockalingam, M. J. Thin Soild Films 1999, 357, 119.

8. Qiao, Z.; Shang, W.; Wang, C. J. Electroanal. Chem. 2005, 576, 171.

9. Rajeshwar, K. Adv. Mater. 1992, 4, 23.

10. Myung, N.; Wei, C.; Rajeshwar, K. Anal. Chem. 1992, 64, 2701.

11. Myung, N.; de Tacconi, N. R.; Rajeshwar, K. Electrochem. Commun. 1999, 1, 42.

12. de Tacconi, N. R.; Rajeshwar, K. J. Elelctroanal. Chem. 1994, 379, 545.

13. Ham, S.; Choi, B.; Myung, N.; de Tacconi, N. R.; Chenthamarakshan, C. R.; Rajeshwar, K.; Son, Y. J. Elelctroanal. Chem. 2005, 574, 367.

14. Han, D.; Choi, S.; Park, S. J. Electrochem. Soc. 2003, 150, C342.

15. Ham, S.; Jeon, S.; Lee, U.; Park, M.; Paeng, K.-J.; Myung, N.; Rajeshwar, K. Anal. Chem. 2008, 80, 6724.

16. Subramanian, B.; Sanjeeviraja, C.; Jayachandran, M. J. Cryst. Growth 2002, 234, 421. 